\title{
Application of Density Functional Theory to the Study of the Reaction of NO with Char-Bound Nitrogen during Combustion
}

\author{
Alejandro Montoya,,$\star \star$ Thanh N. Truong, $*, \S$ and Adel F. Sarofim $*$ \\ Department of Chemistry, University of Antioquia, Medellin, Colombia, A.A 1226, Henry Eyring Center for \\ Theoretical Chemistry, Department of Chemistry, University of Utah, 315 S 1400 E, Room 2020, \\ Salt Lake City, Utah 84112, and Department of Chemical and Fuels Engineering, University of Utah, \\ Salt Lake City, Utah 84112
}

Received: March 20, 2000; In Final Form: June 21, 2000

\begin{abstract}
The reaction of NO with char-bound nitrogen was studied using four model structures to represent the nitrogen left with the char when coal is devolatilized. The calculations were carried out to simulate combustion conditions resulting in the absence and presence of preadsorbed oxygen on the char. Density Functional theory at the B3LYP/6-31G(d) level was used to optimize the geometries of reactants, NO adsorption complexes, and products. Schematic energy profiles for each reaction were obtained in order to elucidate mechanisms for $\mathrm{N}_{2} \mathrm{O}$ evolution. We found that the NO molecule reacts with char-containing nitrogen to release predominantly $\mathrm{N}_{2}$ and $\mathrm{CO}$ to the gas phase. For the model char structures studied, the presence of adsorbed oxygen on the char-containing nitrogen enhances the reduction of the $\mathrm{NO}$ molecule to $\mathrm{N}_{2}$ as a predominant product of the reaction, but $\mathrm{N}_{2} \mathrm{O}$ can also be released as a minor nitrogen product.
\end{abstract}

\section{Introduction}

This study was motivated by the importance of $\mathrm{N}_{2} \mathrm{O}$ in global warming and in stratospheric ozone depletion. One of the anthropogenic sources of $\mathrm{N}_{2} \mathrm{O}$ is the combustion of coal, particularly in fluidized beds, so that it is important to understand the $\mathrm{N}_{2} \mathrm{O}$ formation and reduction mechanism during coal combustion. ${ }^{1}$

The chemistry of the formation of nitrogen oxides during coal combustion is complex and many features are still not fully understood. In general, during the first stage of combustion, volatiles are released during the thermal decomposition of the coal, leaving behind a char residue, with the volatile and char structure and yields determined by the coal chemical structure and the thermal history of the coal. ${ }^{2-4}$ Significant progress has been made in understanding how the volatile nitrogen species can be converted to $\mathrm{N}_{2}, \mathrm{NO}$, and $\mathrm{N}_{2} \mathrm{O}$ by homogeneous reactions with oxygen in the gas phase since the volatile nitrogen is quickly converted to $\mathrm{HCN}$, with minor amounts of ammonia, the combustion chemistry of which has been extensively studied. ${ }^{5}$ The mechanism of the conversion of the nitrogen remaining in the solid char after pyrolysis is less well understood. ${ }^{3,6,7}$ This nitrogen is retained in the char primarily as pyridine and quaternary nitrogen species although pyrrole and $\mathrm{N}$-oxide are also observed. ${ }^{8,9}$ These nitrogen surface species can then be converted to $\mathrm{N}_{2}, \mathrm{NO}$, and $\mathrm{N}_{2} \mathrm{O}$ in the second stage of combustion after reacting with $\mathrm{O}_{2} \cdot{ }^{4,10,11}$ Some studies have tried to relate the evolution of nitrogen oxides with nitrogen groups present in the char before the combustion process. However, no direct relation between the form of the nitrogen in the char and the evolution of nitrogen oxides has yet been found., ${ }^{9,12}$

Despite the long history associated with the study of chemical reactions of nitrogen oxide compounds, ${ }^{5}$ the mechanism of $\mathrm{N}_{2} \mathrm{O}$

$\dagger$ University of Antioquia.

$\doteqdot$ Department of Chemical and Fuels Engineering, University of Utah.

$\S$ Department of Chemistry, University of Utah. evolution from char combustion is not known for certain. Until recently it was believed that NO is released to the gas phase from a heterogeneous solid-gas reaction between char-nitrogen and oxygen. It was postulated that the NO molecules can then be partially reduced to $\mathrm{N}_{2}$ by reacting with the char. The mechanism of the NO reduction has been experimentally ${ }^{13-16}$ and theoretically studied using semiempirical ${ }^{17}$ and ab initio calculations. ${ }^{18}$ By contrast, the mechanism of the $\mathrm{N}_{2} \mathrm{O}$ formation during char combustion remains a question to be resolved. Two different mechanisms have been proposed. One is the heterogeneous reaction of the NO molecule with char- $\mathrm{N}$ in the presence of oxygen to yield $\mathrm{N}_{2} \mathrm{O}$ to the gas phase. ${ }^{11,19,20}$

$$
[\text { char }-\mathrm{N}]+\mathrm{NO} \stackrel{\mathrm{O}_{2}}{\longrightarrow} \mathrm{N}_{2}+\mathrm{N}_{2} \mathrm{O}+\mathrm{CO}
$$

[char-N] denotes nitrogen active site of the char. The other is a homogeneous reaction that follows the release of $\mathrm{HCN}$ from the char. ${ }^{21-25}$

$$
[\text { char }-\mathrm{N}] \stackrel{\mathrm{O}_{2}}{\longrightarrow} \mathrm{HCN} \stackrel{\mathrm{NO}, \mathrm{O}_{2}}{\longrightarrow} \mathrm{N}_{2} \mathrm{O}
$$

First, char-nitrogen is oxidized to release HCN. In the second step, $\mathrm{HCN}$ reacts with $\mathrm{NO}$ molecule in the gas phase to produce $\mathrm{N}_{2} \mathrm{O}$. This mechanism is supported by the measurement of HCN determined just above the reacting sample and their absence at the exit of a thermogravimetric analyzer. ${ }^{26}$ Also, the addition of iodine to the combustion chamber at fluidized bed conditions resulted in decreasing the $\mathrm{N}_{2} \mathrm{O}$ concentration while increasing the $\mathrm{NO}$ and $\mathrm{HCN}$ concentrations. ${ }^{23-25}$ The authors suggested that iodine decreases the radical concentration stopping the second reaction in the (M2) mechanism above. An extended review concerning $\mathrm{N}_{2} \mathrm{O}$ evolution from (M1) and (M2) mechanisms has been recently prepared. ${ }^{27}$ The present study focuses on the (M1) mechanism and examines the evolutions of $\mathrm{N}_{2} \mathrm{O}$, $\mathrm{N}_{2}$, and $\mathrm{CO}$ from the heterogeneous reaction between $\mathrm{NO}$ molecules and carbon-nitrogen systems. 
There are three different mechanisms that have been proposed to explain the formation of $\mathrm{N}_{2} \mathrm{O}$ :

(1) the oxidation of the char-nitrogen to $\mathrm{N}_{2} \mathrm{O}$ by reactions of two adjacent nitrogen groups in the char

$$
\begin{gathered}
\mathrm{O}_{2}+(-\mathrm{C})+(-\mathrm{CN}) \rightarrow \mathrm{C}(\mathrm{O})+(-\mathrm{CNO}) \\
(-\mathrm{CN})+(-\mathrm{CNO}) \rightarrow \mathrm{N}_{2} \mathrm{O}+(-\mathrm{C}) \\
2(-\mathrm{CNO}) \rightarrow \mathrm{C}(\mathrm{O})+\mathrm{N}_{2} \mathrm{O}
\end{gathered}
$$

Here (-*) denotes surface species and $\mathrm{C}(\mathrm{O})$, an oxygen surface complex. This mechanism is not well accepted due to the low probability of having two neighboring $\mathrm{N}$-active sites in the char.

(2) adsorption of an $\mathrm{NO}$ molecule on the char and its reaction with another $\mathrm{NO}$ molecule in order to produce $\mathrm{N}_{2} \mathrm{O}$ by reactions R4 and R5

$$
\begin{aligned}
& (-\mathrm{C})+\mathrm{NO} \rightarrow(-\mathrm{CN})+\mathrm{C}(\mathrm{O}) \\
& (-\mathrm{CN})+\mathrm{NO} \rightarrow \mathrm{N}_{2} \mathrm{O}+(-\mathrm{C})
\end{aligned}
$$

(3) reaction of oxygen with char followed by direct reaction of an NO molecule with char-nitrogen by reactions R6 and R7

$$
\begin{gathered}
\mathrm{O}_{2}+(-\mathrm{C}) \rightarrow \mathrm{C}(\mathrm{O}) \\
\mathrm{C}(\mathrm{O})+(-\mathrm{CN})+\mathrm{NO} \rightarrow \mathrm{N}_{2} \mathrm{O}+\mathrm{C}(\mathrm{O})
\end{gathered}
$$

In this case, the adsorption of oxygen before the reaction of the $\mathrm{NO}$ molecule with char- $\mathrm{N}$ is a very important step in order to form oxygen surface complexes that facilitate $\mathrm{N}_{2} \mathrm{O}$ evolution. Reactions R6 and R7 are well supported experimentally. In a fluidized bed experiment on the combustion of char, when the flow of $\mathrm{O}_{2}$ to the reaction chamber was stopped, the concentration of $\mathrm{N}_{2} \mathrm{O}$ dropped to zero. ${ }^{19} \mathrm{~N}_{2} \mathrm{O}$ was again detected when $\mathrm{O}_{2}$ was resupplied to the reaction chamber. According to the authors, oxygen transforms the nitrogen in the char to an oxygen complex that can release $\mathrm{N}_{2} \mathrm{O}$ to the gas phase after reaction with NO. Unfortunately, in their experiments, the evolution of HCN was not followed so that the two-step mechanism involving the homogeneous mechanism (M2) could also explain these experimental findings. The evolution of $\mathrm{N}_{2} \mathrm{O}$ during the heterogeneous reaction was also consistent with the rates of production in the steady state and in the transient state conditions for the reaction $\mathrm{NO}+(-\mathrm{CNO}) \rightarrow \mathrm{N}_{2} \mathrm{O}+\mathrm{C}(\mathrm{O}) .{ }^{11}$

Further complications arise from the fact that nitrogen can be incorporated into the char structure from reactions of NO, resulting in an increase in the char-nitrogen content during oxidation. Such reactions are particularly important at temperatures of around $800-1000 \mathrm{~K}$ below the conventional temperatures of operation, $1200-1400 \mathrm{~K}$, of fluidized beds. As the temperature is increased, the complexes are expected to become mobile and provide additional difficulty in analyzing the results.

The experimental results on $\mathrm{NO}$ and $\mathrm{N}_{2} \mathrm{O}$ formation vary widely with char type and experimental conditions. Past approaches of formulating surface sites and complexes have at best been able to rationalize results and have not been able to anticipate data obtained with different carbons and different experimental conditions. Resolution of the various hypotheses can be guided by studying $\mathrm{N}_{2} \mathrm{O}$ evolution using modern quantum chemistry theory. Particularly, density functional theory (DFT) is used in order to obtain schematic energy profiles for the different possible channels for the reaction between the NO molecule with char-containing nitrogen. Different models of the char were used in order to study the three different heterogeneous mechanisms proposed experimentally. Although our focus
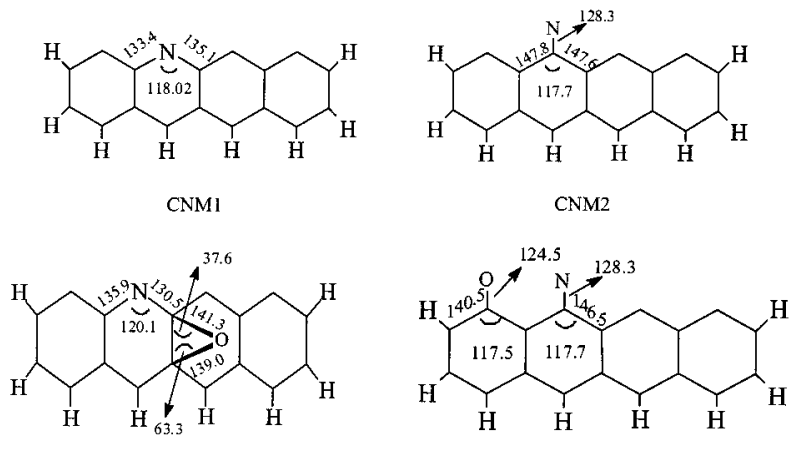

$\mathrm{CN} / \mathrm{OM} 1$

$\mathrm{CN} / \mathrm{OM} 2$

Figure 1. Models for nitrogen-containing char. The oxygen in the CN/ OM1 model is perpendicular to the carbon plane. Numbers represent selected optimized geometrical parameters at the B3LYP/6-31G(d) level. Bond lengths in picometers and bond angles in degrees.

is on the $\mathrm{N}_{2} \mathrm{O}$ formation, the evolution of other species, namely $\mathrm{N}_{2}$ and $\mathrm{CO}$, was also evaluated. It should be noted that chars have a wide range of structures and compositions so that the present study can only examine a small subset of alternative structures. It is felt that studies such as these for the different proposed structures for coal chars can provide the mechanisms needed to explain the paths for the heterogeneous char-nitrogen reactions with oxygen and $\mathrm{NO}$ in addition to those involving the release of char-nitrogen as $\mathrm{HCN}$ followed by homogeneous reactions between the $\mathrm{HCN}$ and $\mathrm{NO}$ and oxygen. In this paper we consider only the heterogeneous path.

\section{Computational Details}

Physical Models of the Active Sites. Four different molecular systems were proposed and are presented in Figure 1. Model CNM1 (carbon-nitrogen, model 1) with nitrogen in the pyridine group represents the reaction of NO with the carbon-nitrogen system in the absence of oxygen (reaction R5). Model CNM2 with nitrogen bonded to carbon, forming a cyanide-like group, represents the reaction of $\mathrm{NO}$ in the presence of oxygen. The role of oxygen in this case would be to oxidize neighboring carbon atoms to form $\mathrm{CO}$ and to expose the $\mathrm{N}$ atom in the form of a cyanide group. Model CN/OM1 (carbon-nitrogen system with preadsorbed oxygen, model 1) contains nitrogen in a pyridine-like group and oxygen in an epoxy group. It represents a molecular system for the reaction of NO in the presence of preadsorbed oxygen. The off-plane epoxy oxygen was proposed from previous theoretical studies as an oxygen surface complex that can be more reactive than other types of oxygen complexes such as semiquinones and carbonyls that can be formed on the carbonaceous surface after reaction with oxygen. ${ }^{28}$ The role of oxygen in this case would be to facilitate the reaction of $\mathrm{C}(\mathrm{N})$ species with the NO molecule, reactions R6 and R7. Model CN/ OM2 is designed to study reactions R4 and R5. This molecular system can represent two possibilities: the formation of a semiquinone group by reaction of the carbon with oxygen near the nitrogen surface atom or the dissociative NO adsorption on char, as suggested by Kiotany et al. ${ }^{18}$ In all molecular systems, the carbon atoms in the top edge are unsaturated in order to simulate the free active sites in char. ${ }^{29}$

The four model compounds selected represent pyridinic and $\mathrm{CN}$ nitrogen groups, pyridinic nitrogen because this group has been observed to be a dominant group and $\mathrm{CN}$ because of the indirect observation of $\mathrm{HCN}$ formation. Additional functional forms of nitrogen that need to be addressed are pyrrolic and quaternary. The carbon structure also represents a subset of 
TABLE 1: Statistical Geometrical Analysis for Char-Nitrogen Models (Bond Lengths in Picometers and Angles in Degrees) ${ }^{a}$

\begin{tabular}{|c|c|c|c|c|c|c|}
\hline \multicolumn{2}{|l|}{ parameter } & CNM1 & CNM2 & CN/OM1 & CN/OM2 & $\exp ^{b}$ \\
\hline $\mathrm{C}-\mathrm{C}$ & av & 141.2 & 141.3 & 141.5 & 141.9 & 142 \\
\hline & $\sigma$ & 0.04 & 0.06 & 0.04 & 0.03 & \\
\hline $\mathrm{C}-\mathrm{H}$ & av & 108.7 & 108.6 & 108.5 & 108.7 & 107 \\
\hline$\angle \mathrm{C}-\mathrm{C}-\mathrm{C}$ & $\begin{array}{l}\sigma \\
\text { av }\end{array}$ & $\begin{array}{l}0.0004 \\
120.4 \\
324\end{array}$ & $\begin{array}{l}0.0004 \\
123.2 \\
43\end{array}$ & $\begin{array}{l}0.0003 \\
120.7 \\
34\end{array}$ & $\begin{array}{l}0.0008 \\
120.4\end{array}$ & 120 \\
\hline$\angle \mathrm{C}-\mathrm{C}-\mathrm{H}$ & $\begin{array}{l}O \\
\text { av }\end{array}$ & $\begin{array}{l}3.24 \\
120.2\end{array}$ & $\begin{array}{l}4.3 \\
119.5\end{array}$ & $\begin{array}{l}3.4 \\
119.8\end{array}$ & $\begin{array}{l}3.0 \\
119.9\end{array}$ & 120 \\
\hline dihedral & $\sigma$ & $\begin{array}{l}1.1 \\
\text { planar }\end{array}$ & $\begin{array}{l}1.6 \\
\text { planar }\end{array}$ & $\begin{array}{l}2.1 \\
\text { nonplanar }\end{array}$ & $\begin{array}{l}1.5 \\
\text { planar }\end{array}$ & planar \\
\hline
\end{tabular}

configurations that are important in coals. Other studies will be needed (a) to show the effects of varying the polybenzenoid structure to represent the wide range found in coals of different ranks, (b) to include armchair as well as zigzag carbon configuration, (c) to study the impact of different heteroatoms and substituents on the aromatic rings, and (d) to consider other oxygen functional groups such as carboxylic and carbonyl.

Theoretical Model. To elucidate mechanisms for $\mathrm{N}_{2}, \mathrm{CO}$, and $\mathrm{N}_{2} \mathrm{O}$ evolution for the model chars selected above, we have determined structures and energies of different possible surface complexes and product species. This provides a thermodynamic, not kinetic, argument on the dominant pathways. Different NO adsorption complexes were optimized by allowing NO approaching the carbon-nitrogen models from different directions. All calculations were done at the B3LYP DFT level of theory where B3LYP stands for Becke's three-parameter nonlocal exchange functional ${ }^{30}$ with the nonlocal correlation functional of Lee, Yang, and Parr, ${ }^{31}$ using the 6-31G(d) basis set. It is known that B3LYP produces fairly accurate bond energies and thermodynamic properties of reactions. The unrestricted openshell wave function was used in all open-shell cases. It should be pointed out that in our recent study, ${ }^{32}$ the spin contamination in the unrestricted B3LYP is reasonably small and has acceptable small affects on the energetic properties. In fact, we found the magnitude of the spin contamination defined by the difference between the expected value of the $\mathbf{S}^{2}$ operator and its eigenvalue $S(S+1)$ to be about 0.09 in all cases. The unrestricted Hartree-Fock method, however, has a significantly large spin contamination and thus it was not employed in this study. A more detailed examination of the spin contamination in UHF and DFT methods for modeling adsorption on char can be found in a separate report. ${ }^{32}$ In addition, before optimizing reactants, intermediates, and products for the ground state, we have performed single-point energy calculations using optimized geometries at a lower level of theory for estimating energies at different electronic states to determine the correct ground state. All calculations were done using the GAUSSIAN 98 program. ${ }^{33}$

\section{Results}

Carbon-Nitrogen Models. The four char-nitrogen models shown in Figure 1 were fully optimized. The most important optimized geometrical parameters are shown in the figure and the statistical analysis of the remaining part is shown in Table 1. Although each molecular system contains a nitrogen atom bonded to the carbonaceous matrix, the $\mathrm{C}-\mathrm{C}$ and $\mathrm{C}-\mathrm{H}$ bond lengths and $\mathrm{C}-\mathrm{C}-\mathrm{C}$ and $\mathrm{C}-\mathrm{C}-\mathrm{H}$ bond angles are in very good agreement with those obtained experimentally for graphite. ${ }^{34}$ The CNM1, CNM2, and CN/OM2 molecular systems are predicted to be planar. The CN/OM1 model with the oxygen atom in the epoxy type was found to be nonplanar. This is in
TABLE 2: Statistical Geometrical Analysis for the NO Intermediates (Bond Lengths in Picometers and Angles in Degrees) ${ }^{a}$

\begin{tabular}{lllrrrrrr}
\hline parameter & & \multicolumn{1}{c}{$\mathrm{A}$} & \multicolumn{1}{c}{$\mathrm{B}$} & \multicolumn{1}{c}{$\mathrm{C}$} & \multicolumn{1}{c}{$\mathrm{DE}$} & $\mathrm{F}$ & \multicolumn{1}{c}{$\mathrm{G}$} & \multicolumn{1}{c}{$\mathrm{H}$} \\
\hline $\mathrm{C}-\mathrm{C}$ & av & 140.6 & 141.3 & 140.9 & 140.9 & 140.6 & 140.8 & 140.9 \\
& $\sigma$ & 0.03 & 0.03 & 0.04 & 0.03 & 0.03 & 0.03 & 0.02 \\
$\mathrm{C}-\mathrm{H}$ & av & 108.6 & 108.9 & 109.2 & 108.7 & 108.7 & 108.7 & 108.6 \\
& $\sigma$ & 0.0007 & 0.0005 & 0.002 & 0.0004 & 0.004 & 0.0006 & 0.0005 \\
$\angle \mathrm{C}-\mathrm{C}-\mathrm{C}$ & av & 119.9 & 120.1 & 121.6 & 119.4 & 121.2 & 122.2 & 120.4 \\
& $\sigma$ & 3.9 & 2.9 & 3.1 & 3.8 & 3.8 & 4.5 & 3.8 \\
$\angle \mathrm{C}-\mathrm{C}-\mathrm{H}$ & av & 119.7 & 120.3 & 119.8 & 119.8 & 119.4 & 119.4 & 120.4 \\
& $\sigma$ & 1.6 & 1.5 & 1.6 & 1.3 & 1.7 & 1.6 & 1.6 \\
dihedral & & planar & planar & planar & plane & nonplanar & nonplanar & planar
\end{tabular}

${ }^{a}$ av $=$ average. $\sigma=$ standard deviation.

agreement the result from UHF calculations done by Chen and Yang. ${ }^{35}$ The $\mathrm{C}-\mathrm{N}$ bond length and $\mathrm{C}-\mathrm{N}-\mathrm{C}$ bond angle for the CNM1 and CN/OM1 models are in agreement with those of $134.0 \mathrm{pm}$ and $116.8^{\circ}$, respectively, obtained experimentally for isolated pyridine. ${ }^{36}$ The agreement between geometrical parameters shows a pyridinic character for these two nitrogencontaining char models. Note that the CN/OM1 model would not be adequate to model the electronic structure of the epoxy group. However, our main interest is not in the epoxy group but in its secondary effects, namely, the effects of the epoxy oxygen on the adsorption properties of NO. For such a purpose, the CN/OM1 model would be adequate. This is confirmed by noticing that the geometry of the epoxy group remains almost unaltered upon adsorption of $\mathrm{NO}$ at the active site, as discussed below. In addition, we have optimized the geometry of a larger model, which has two rows of benzene rings rather than one, as in the CN/OM1 model. We found that the degree of nonplanarity changes a little whereas the geometry of the epoxy oxygen relative to the basal plane has larger changes. Thus, we only expect to obtain a semiqualitative trend of its effects. Since the epoxy group has not been observed experimentally, such accuracy is sufficient for our purpose here. The $\mathrm{C}-\mathrm{N}$ bond lengths for CNM2 and CN/OM2 models are the shortest in the molecular system, having a cyanide character. Notice also that the nearest $\mathrm{C}-\mathrm{C}$ bond length to the $\mathrm{C}-\mathrm{N}$ bond is on average $5.7 \mathrm{pm}$ longer than the average $\mathrm{C}-\mathrm{C}$ bond length. This indicates that the $\mathrm{C}-\mathrm{C}$ bond closest to the $\mathrm{C}-\mathrm{N}$ bond is the weakest one in the molecular system. This suggests a possible mechanism for $\mathrm{CN}$ release from a breaking these two $\mathrm{C}-\mathrm{C}$ bonds.

The size of the carbon-nitrogen model is an important fact in modeling adsorption on graphite. Chen and Yang, ${ }^{29}$ using the HF level of theory selected a model, $\mathrm{C}_{25} \mathrm{H}_{9}$, as the best molecular system that yielded structural parameters close to experimental data for graphite. In our case, to improve the calculated energetic properties and avoid the spin contamination problem in the UHF wave function, the molecular system was decreased to $\mathrm{C}_{18} \mathrm{H}_{8}$, including nitrogen and oxygen in some cases. Even at this size, the statistical geometrical parameters for the carbon-nitrogen models (Table 1) are in agreement within the estimated experimental uncertainty for graphite. ${ }^{34}$ On the other hand, from a comparison of the statistical analysis of carbon-nitrogen models with the statistical analysis for the NO adsorption intermediates (Table 2), it is clear that there are not considerable changes in the bond lengths and bond angles. The adsorption of the NO molecule affects only the geometry of the atoms near the adsorption site. Also, the hydrogen termination does not interact with epoxy oxygen on the basal plane. These results show that the molecular systems used in this study are adequate.

Reaction with NO Molecule in the Absence of Oxygen. The adsorption of $\mathrm{NO}$ on the CNM1 model represents the 

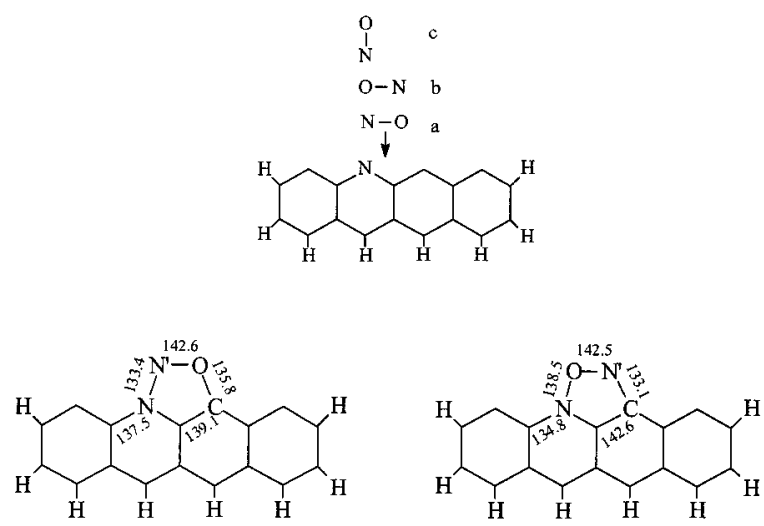

A

B

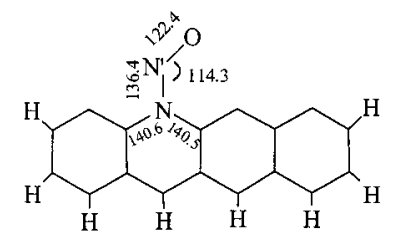

C

Figure 2. Orientations for $\mathrm{NO}$ adsorption and $\mathrm{NO}$ adsorption complexes on the CNM1 model. $\mathrm{N}^{\prime}$ is the nitrogen atom originated from the NO molecule. Numbers represent selected optimized geometrical parameters. Bond lengths in picometers and bond angles in degrees.

interaction between an NO molecule in the gas phase with nitrogen on the solid surface in the absence of oxygen. Three different relative orientations of NO for adsorption on the CNM1 model, shown as "a", "b", and "c" in Figure 2, were examined. These lead to three possible surface complexes, namely A, B, and $\mathrm{C}$, respectively. These surface complexes were found to be planar and are shown in Figure 2 where some relevant optimized geometrical parameters are also reported. The statistical analysis of the remaining part is shown in Table 2 . The prime on nitrogen is used to differentiate nitrogen from the NO molecule and nitrogen from the CNM1 model. Intermediates A and B form five-membered rings between the NO molecule and nitrogen model while Intermediate $\mathrm{C}$ does not. The $\mathrm{N}^{\prime}-\mathrm{O}$ bond lengths of intermediates A and B are stretched by $29 \%$ compared to the NO equilibrium bond length. This implies a possible dissociative chemisorption of $\mathrm{NO}$ to form a semiquinone and cyanide group. On the contrary, for complex $\mathrm{C}$ the $\mathrm{N}^{\prime}-\mathrm{O}$ bond length is stretched by $6.4 \%$ from the equilibrium $\mathrm{NO}$ bond length. Notice the $\mathrm{C}-\mathrm{N}$ bonds in complex $\mathrm{C}$ are elongated by $7.1 \mathrm{pm}$ upon adsorption of NO. This indicates a weakening of these bonds and thus leads to a possible pathway for the release of $\mathrm{N}_{2} \mathrm{O}$.

Different paths of desorption can be considered from these three intermediates. (i) Desorption of $\mathrm{N}_{2}$ from intermediate $\mathrm{A}$ with a 1,3-oxygen migration into the model framework to form an ether group (Figure 3-1). An ether type complex was suggested as one of the oxygen complexes formed after reaction of carbonaceous material with $\mathrm{O}_{2} \cdot{ }^{37}$ In this case $\mathrm{N}_{2}$ consists of nitrogen from the NO molecule and from the CNM1 model. This reaction pathway is supported by $\mathrm{N}$-isotope labeled experiments that suggest the main mechanism for $\mathrm{N}_{2}$ evolution involves the combination of a nitrogen from the $\mathrm{NO}$ molecule with that from a $\mathrm{C}(\mathrm{N})$ group in the solid phase. ${ }^{13,14,16}$ (ii) $\mathrm{CO}$ released from $\mathrm{A}$ accompanied by an 1,3 nitrogen migration to the nitrogen model, forming two pyridine rings, as shown in Figure $3-\mathrm{m}$. In this way $\mathrm{CO}$ is formed with the oxygen from

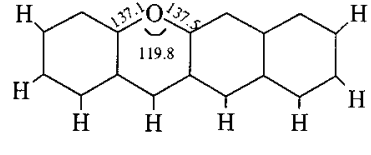

(I)

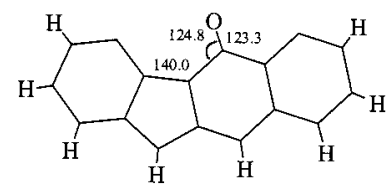

(1)

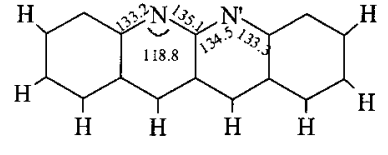

(m)

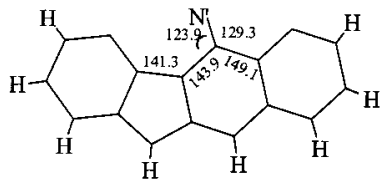

(o)

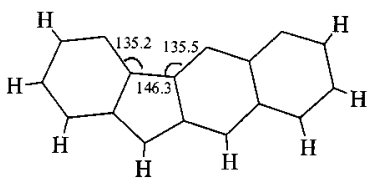

(p)

Figure 3. Products from different desorption pathways after adsorption of the NO molecule on CNM1 model. Numbers represent selected optimized geometrical parameters. Bond lengths in picometers and bond angles in degrees.

the NO molecule and the nitrogen is incorporated into the char. The evolution of $\mathrm{CO}$ where oxygen comes from the NO molecule was also determined from an isotopic labeled experiment. ${ }^{38}$ Also, the incorporation of nitrogen from an NO molecule into the solid phase during the reaction of the NO molecule with a carbonaceous material was observed experimentally. The predominant nitrogen groups were pyridinic and pyrrolic. ${ }^{15,39}$ (iii) $\mathrm{N}_{2}$ evolution from intermediate $\mathrm{A}$, forming a five-membered ring and semiquinone group Figure 3-n. (iv) Evolution of NO from intermediate $\mathrm{B}$ where surface nitrogen interchanges with that of the NO molecule (Figure 3-o). (v) Similar process to (iv) but followed by an 1,3 nitrogen migration to reform the CNM1 structure. This is considered to be an isotope exchange reaction. (vi) Evolution of $\mathrm{N}_{2} \mathrm{O}$ from intermediate $\mathrm{C}$, forming a five-membered ring (Figure 3-p). In this case, $\mathrm{N}_{2} \mathrm{O}$ evolution will consist of nitrogen from the $\mathrm{NO}$ molecule and nitrogen from the model CNM1. ${ }^{15} \mathrm{~N}^{14} \mathrm{NO}$ was detected using ${ }^{15} \mathrm{~N}$ isotoped labeled NO at fluidized bed conditions (FBC), although the authors explain this evolution as a consequence of the homogeneous reaction of cyanide groups released from the char before the reaction with the NO molecule in order to produce $\mathrm{N}_{2} \mathrm{O}$ in gas phase. ${ }^{40}$

Figure 4 shows the schematic energy profiles for all the above-mentioned pathways. Reactants, intermediates, and products are connected with dotted lines, indicating that transition states connecting these stable species have not been determined. In this figure, the energy of the optimized structures is relative to the reactants. As can be seen, the stability of intermediates is in the order $\mathrm{A}>\mathrm{B}>\mathrm{C}$. Adsorption of NO in the side-on orientation is preferred compared to the $\mathrm{N}$-down one, in agreement with the results obtained by Kyotani et al. ${ }^{18}$ The nitrogen-nitrogen adsorption, intermediate $\mathrm{A}$, is more stable than the nitrogen-oxygen adsoprtion, intermediate $\mathrm{B}$, by 16.2 $\mathrm{kcal} / \mathrm{mol}$. The formations of the three A, B, and C intermediates are exothermic processes with exothermicities of 48.0, 31.8, and $3.0 \mathrm{kcal} / \mathrm{mol}$, respectively. Reaction paths $\mathrm{i}$ and ii, forming products 1 and $\mathrm{m}$, respectively, are the dominant pathways under the conditions studied. The evolutions of $\mathrm{N}_{2}$ and $\mathrm{CO}$ from intermediate $\mathrm{A}$ are exothermic processes with reaction energies of -50.1 and $-44.1 \mathrm{kcal} / \mathrm{mol}$, respectively. The evolution of 


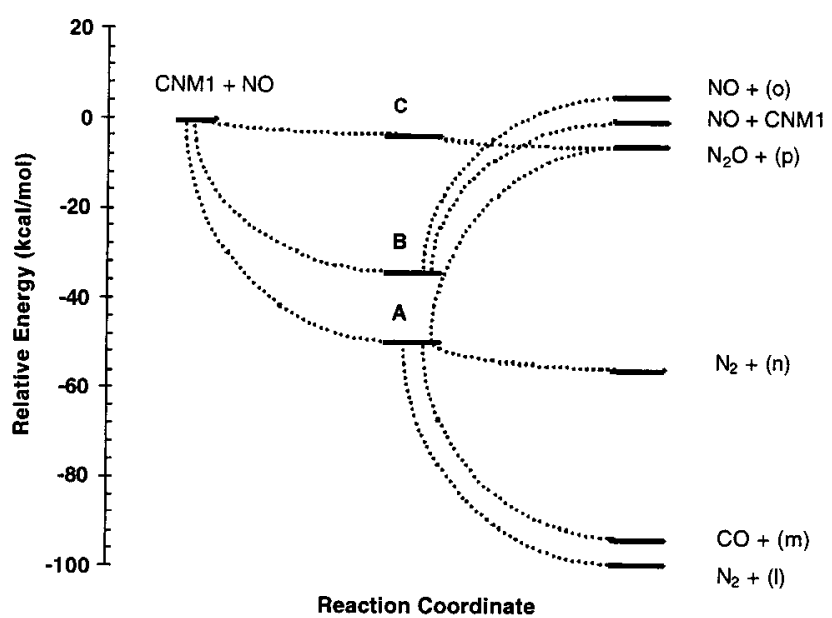

Figure 4. Schematic energy profiles of different pathways for reactions of NO on the CNM1 model. The energy is relative to the reactants.
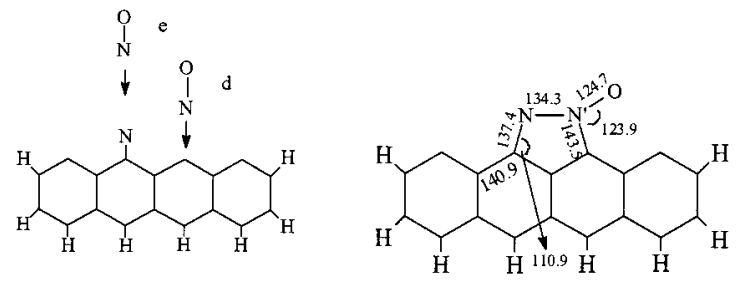

DE

Figure 5. Orientations for $\mathrm{NO}$ adsorption and $\mathrm{NO}$ adsorption complexes on the CNM2 model. $\mathrm{N}^{\prime}$ is the nitrogen atom originated from the NO molecule. Numbers represent selected optimized geometrical parameters. Bond lengths in picometers and bond angles in degrees.

$\mathrm{N}_{2}$ forming a five-membered ring and semiquinone group (structure $n$ ) is also possible, but it is a less probable pathway. Pathways for the evolution of NO molecule from intermediate $\mathrm{B}$ to regenerate the CNM1 model and product o are endothermic processes with endothermicities of 38.1 and $44.6 \mathrm{kcal} / \mathrm{mol}$, respectively. This suggests that the isotopic $\mathrm{N}$-interchanging is a very difficult process. The evolution of $\mathrm{N}_{2} \mathrm{O}$ from intermediate $\mathrm{C}$ is an exothermic process of $2 \mathrm{kcal} / \mathrm{mol}$. Although this channel of reaction is energetically plausible, the reduction of the NO molecule to $\mathrm{N}_{2}$ and $\mathrm{CO}$, forming products 1 and $\mathrm{m}$ are the dominant channels. If the $\mathrm{NO}$ molecule approaches the nitrogen in the $\mathrm{N}$-down orientation, some of the $\mathrm{NO}$ intermediates will produce $\mathrm{N}_{2} \mathrm{O}$ to the gas phase but most of them will generate intermediate $\mathrm{A}$ to release $\mathrm{N}_{2}$ and $\mathrm{CO}$ molecules. $\mathrm{N}_{2} \mathrm{O}$ can also be released from intermediate A, as shown in Figure 4, but the breaking of three bonds, the two $\mathrm{C}-\mathrm{N}$ and one $\mathrm{C}-\mathrm{O}$, simultaneously makes it an endothermic process of $43.2 \mathrm{kcal} /$ mol. In summary, the reduction of the NO molecule to $\mathrm{N}_{2}$ with nitrogen on the surface is the most dominant path of reaction in this model. Another important result is that NO adsorption prefers the orientation that forms the $\mathrm{N}-\mathrm{N}$ bond. Thus, for adsorption of NO on other models, we only focus on this particular orientation.

Different orientations, as shown in Figure 5, were examined for the adsorption of the NO molecule on the CNM2 model. Both adsorption directions converged to the same minimum on the potential surface, namely, the planar intermediate DE, as shown in Figure 5. The adsorption of the NO molecule forms a five-membered ring between nitrogen from the NO molecule and the CNM2 model. Selected geometrical parameters are shown in Figure 5 and the statistical analysis of the remaining part is shown in Table 2. NO adsorption shortens the $\mathrm{C}-\mathrm{C}$ bond
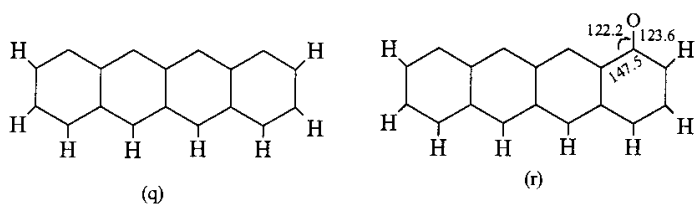

Figure 6. Products from different desorption pathways after adsorption of the NO molecule on the CNM2model. Numbers represent selected optimized geometrical parameters. Bond lengths in picometers and bond angles in degrees.

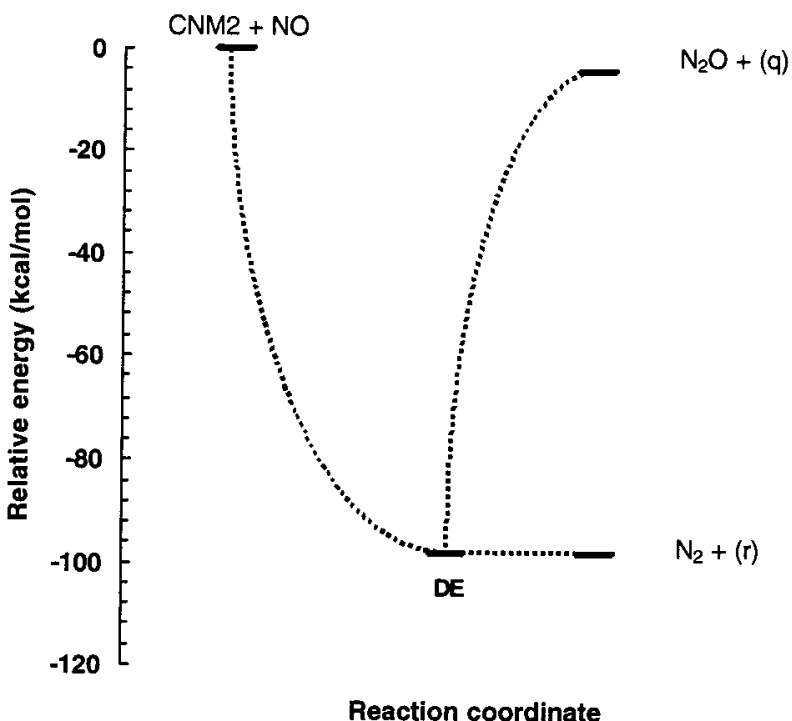

Figure 7. Schematic energy profiles of different pathways for reactions of $\mathrm{NO}$ on the CNM2model. Energy is relative to the reactants.

near the $\mathrm{C}-\mathrm{N}$ bond by $6.8 \mathrm{pm}$, while elongating the $\mathrm{C}-\mathrm{N}$ bond of the char by $9.1 \mathrm{pm}$. The $\mathrm{C}-\mathrm{C}-\mathrm{N}$ bond angle changes from 120 to $110.9^{\circ}$ due to strong interaction with the NO molecule. The rest of the molecule remains almost unchanged.

Two desorption pathways were considered here, namely (i) desorption of $\mathrm{N}_{2} \mathrm{O}$ by breaking two $\mathrm{C}-\mathrm{N}$ bonds, forming a carbonaceous product, as shown in Figure 6-q and (ii) 1,4 oxygen migration from the nitrogen ring to the carbonaceous structure to form a semiquinone group as shown in Figure 6-r and desorption of $\mathrm{N}_{2}$. Figure 7 shows the schematic energy profiles for the reaction between the CNM2 model and the NO molecule. Intermediate $\mathrm{DE}$ is a very stable structure with the adsorption energy of $97.2 \mathrm{kcal} / \mathrm{mol} . \mathrm{N}_{2} \mathrm{O}$ evolution is obtained with an endothermicity of $92.0 \mathrm{kcal} / \mathrm{mol}$, while $\mathrm{N}_{2}$ can be released with an endothermicity of $0.8 \mathrm{kcal} / \mathrm{mol}$ from intermediate DE. Thus, in this model, the role of oxygen from the NO molecule is to oxidize the carbon atom close to the nitrogen atom and to facilitate $\mathrm{N}_{2}$ release.

Reaction of the NO Molecule in the Presence of Adsorbed Surface Oxygen. The following discussion considers the adsorption of the NO molecule on char-nitrogen models with preadsorbed oxygen atoms. Model CN/OM1 presents the effect of the preadsorption of oxygen in the epoxy group. Two orientations " $\mathrm{f}$ " and "g" for NO approaching the surface yield intermediates F and G, respectively, as shown in Figure 8. Some optimized geometrical parameters are also included. The statistical analysis of the remaining part is shown in Table 2. Similarly to the CN/OM1 model, the CN/OM1 intermediates are not planar. In both cases, the epoxy group is above the carbon plane while the $\mathrm{N}^{\prime}-\mathrm{O}$ group is below the carbon plane. Some changes on the intermediates in comparison with the CN/OM1 model are observed. In particular, the adsorption of the NO molecule increases the $\mathrm{C}-\mathrm{N}$ bond lengths by about $7.6 \mathrm{pm}$ on average. 


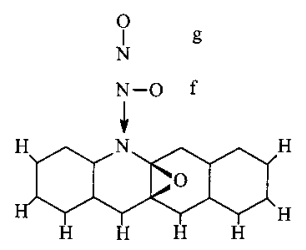

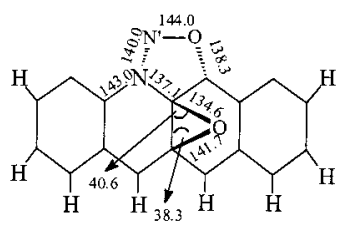

F

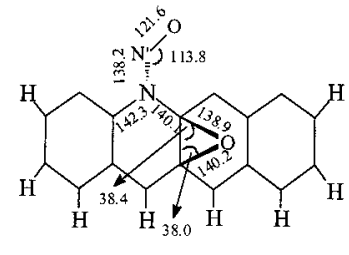

G
Figure 8. Orientations for NO adsorption and NO adsorption complexes on the $\mathrm{CN} / \mathrm{OM} 1$ model. $\mathrm{N}^{\prime}$ is the nitrogen atom originated from the NO molecule. Numbers represent selected optimized geometrical parameters. Bond lengths in picometers and bond angles in degrees.

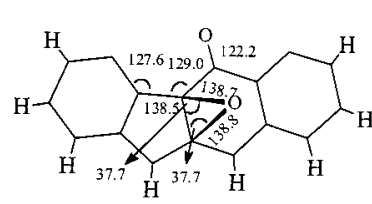

(s)

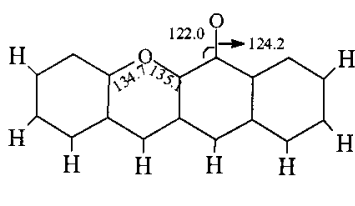

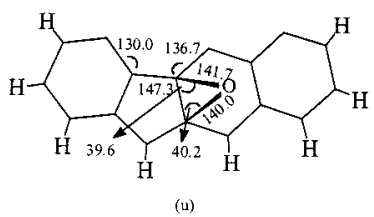

Figure 9. Products from different desorption pathways after adsorption of the NO molecule on the CN/OM1 model. Numbers represent selected optimized geometrical parameters. Bond lengths in picometers and bond angles in degrees.

The geometrical parameters for the epoxy oxygen are changed in such a way that the atom moves toward the unsaturated carbons. Notice also that the two angles shown in the figure for the epoxy group in each intermediate are almost the same. It suggests that hydrogen termination in the first row of a sixmembered ring does not interact considerably with the epoxy group in the basal plane. The adsorption of the NO molecule in the " $\mathrm{f}$ " orientation produces the complex $\mathrm{F}$ with a fivemembered ring where the $\mathrm{N}^{\prime}-\mathrm{O}$ bond is the longest in the fivemembered ring similar to intermediate A. Similarly, the adsorption in the "g" orientation produces $\mathrm{G}$ similar to intermediate $\mathrm{C}$.

Several desorption pathways from the NO-adsorbed complexes $\mathrm{F}$ and $\mathrm{G}$ have been examined. First, $\mathrm{N}_{2}$ is desorbed from the complex $\mathrm{F}$ by breaking the long $\mathrm{N}^{\prime}$-O bond to form a fivemembered ring and a semiquinone group, Figure 9-s. The epoxy oxygen remains the same characteristic in product s. Second, the complex $\mathrm{F}$ can also desorb $\mathrm{N}_{2}$, but in this case the epoxy oxygen transforms into an ether group and the oxygen from the NO molecule remains in the surface, forming a semiquinone group, Figure 9-t. Third, $\mathrm{N}_{2} \mathrm{O}$ is desorbed by breaking two $\mathrm{C}-\mathrm{N}$ bonds from intermediate $\mathrm{G}$ to form a five-membered ring, Figure 9-u. The epoxy oxygen retains its characteristic in product $u$. Fourth, desorption of $\mathrm{N}_{2} \mathrm{O}$ from intermediate $\mathrm{G}$ where the epoxy oxygen transform into an ether group, Figure 3-1. Comparison of intermediates $\mathrm{F}$ and $\mathrm{G}$ with products $\mathrm{s}$ and $\mathrm{u}$ indicates that

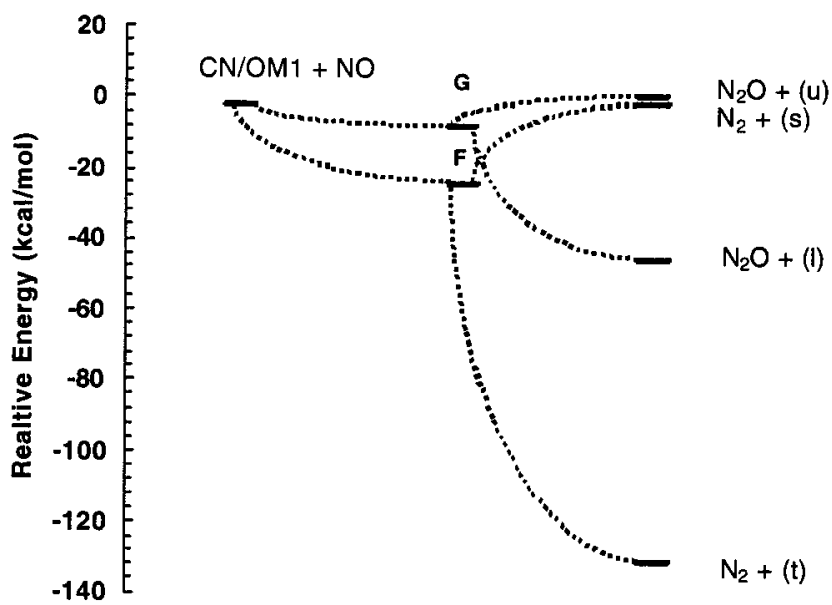

Reaction coordinate

Figure 10. Schematic energy profiles of different pathways for reactions of $\mathrm{NO}$ on the $\mathrm{CN} / \mathrm{OM} 1$ model. The energy is relative to the reactants.

the bond angles of the epoxy groups remain almost unaltered. This suggests that the geometry of the epoxy oxygen is not very sensitive to the nature of the active site. This result supports the use of the CN/OM1 model in this study. However, it does not imply that the epoxy oxygen cannot transform into an ether group on the carbonaceous surface. Furthermore, the ether group in product $\mathrm{t}$ is predicted to be more stable than the epoxy oxygen in five-membered ring product s by $133.1 \mathrm{kcal} / \mathrm{mol}$. Figure 10 shows the schematic energy profiles for the NO adsorption on the CN/OM1 model. Both intermediates $\mathrm{F}$ and $\mathrm{G}$ are formed as stable complexes. Similar to the NO adsorption on the CNM1 model, the side-on orientation is preferred compared to the $\mathrm{N}$-down one. Intermediate $\mathrm{F}$ (side-on adsorption) is formed with an exothermicity of $20.0 \mathrm{kcal} / \mathrm{mol}$, while intermediate $\mathrm{G}(\mathrm{N}$ down adsorption) is formed with an exothermicity of $4.6 \mathrm{kcal} /$ mol. Notice that the energy difference between these two intermediates $(15.4 \mathrm{kcal} / \mathrm{mol})$ is smaller than the energy difference of $45 \mathrm{kcal} / \mathrm{mol}$ between the $\mathrm{A}$ and $\mathrm{C}$ intermediates. Two desorption pathways from these intermediates are important, namely pathways one and four, as discussed above, that yield $\mathrm{N}_{2}$ and $\mathrm{N}_{2} \mathrm{O}$ gases. In particular, $\mathrm{N}_{2}$ and $\mathrm{N}_{2} \mathrm{O}$ evolutions are predicted to be spontaneous reactions with exothermicities of 93.3 and $38.9 \mathrm{kcal} / \mathrm{mol}$, respectively. The schematic energy profiles suggest that most of the NO reacting on the surface solid will be reduced to $\mathrm{N}_{2}$ and some will be reduced to $\mathrm{N}_{2} \mathrm{O}$ by nitrogen on the surface. Under the conditions studied, $\mathrm{N}_{2} \mathrm{O}$ and $\mathrm{N}_{2}$ evolution from the reaction of $\mathrm{NO}$ on a carbon-oxygen surface complex is thermodynamically favored. Comparing the $\mathrm{N}_{2}$ energy desorption from intermediate $\mathrm{F}$ with $\mathrm{N}_{2}$ energy desorption from intermediate A (Figure 4), one can see that the epoxy oxygen enhanced the NO reduction to $\mathrm{N}_{2}$ by lowering the exothermicity by $43.1 \mathrm{kcal} / \mathrm{mol}$. In this case the preadsorption of oxygen before reacting with $\mathrm{NO}$ is an important fact for $\mathrm{N}_{2} \mathrm{O}$ and $\mathrm{N}_{2}$ evolutions.

The adsorption of the NO molecule on the model CN/OM2 is described in Figure 11. This adsorption process is similar to that studied by Kyotani and Tomita ${ }^{18}$ using the B3LYP//UHF level of theory (B3LYP single-point energy calculations at UHF optimized geometries) on a larger molecular system than the CN/OM2 model. Our recent study showed that spin contamination is significant in the UHF wave function for this system and has large effects on the adsorption properties. Thus, one can expect B3LYP and UHF methods would predict different NO adsorption geometry. Unfortunately, previous study did not 

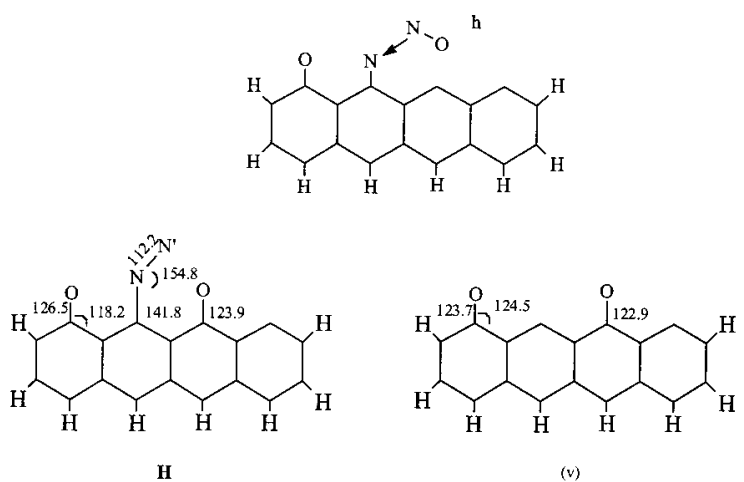

Figure 11. Orientations for NO adsorption (left) and NO adsorption complex (right) on the $\mathrm{CN} / \mathrm{OM} 2$ model. $\mathrm{N}^{\prime}$ is the nitrogen atom originated from the NO molecule. Numbers represent selected optimized geometrical parameters. Bond lengths in picometers and bond angles in degrees.

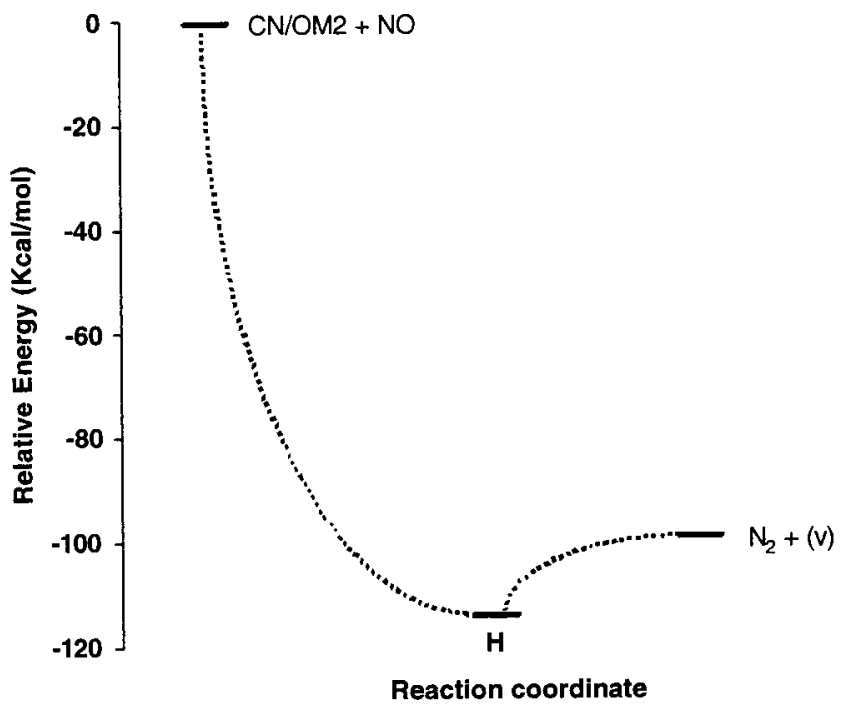

Figure 12. Schematic energy profiles of different pathways for reactions of $\mathrm{NO}$ on the $\mathrm{CN} / \mathrm{OM} 2$ model. The energy is relative to the reactants.

report UHF optimized geometries of the corresponding NO adsorption complexes for comparisons with the present results. In our case, $\mathrm{NO}$ adsorption yields the surface complex that has a planar structure as shown in Figure 11-H. This figure includes some optimized geometrical parameters, and the statistical analysis of the remaining part is shown in Table 2. Contrary to the previous UHF results, ${ }^{18}$ we found a dissociative NO chemisorption where the oxygen from the $\mathrm{NO}$ molecule was bonded to the CN/OM2 model as a semiquinone group and the nitrogen was strongly bonded to the nitrogen in the model. The possibility of $\mathrm{N}_{2}$ evolution from the $\mathrm{H}$ intermediate allows for the formation of product $\mathrm{v}$ shown in Figure 11. This structure has the two oxygens forming two semiquinone groups where the $\mathrm{C}-\mathrm{O}$ bond is a little shorter than that in intermediate $\mathrm{H}$. The Mulliken population analysis of complex $\mathrm{H}$ done by Kyotani and Tomita showed that the NO bond population is very small and the $\mathrm{CN}$ bond is weakened. From these, the authors had suggested the possibly for $\mathrm{N}_{2}$ desorption, consistent with our results. The evolution of $\mathrm{N}_{2} \mathrm{O}$ from this intermediate is not possible due to the dissociative chemisorption of the NO molecule. The energetic profile for $\mathrm{N}_{2}$ evolution is shown in Figure 12. Intermediate $\mathbf{H}$ is a very stable complex with the adsorption energy of $-113 \mathrm{kcal} / \mathrm{mol}$, and the $\mathrm{N}_{2}$ evolution is obtained with an endothermicity of $15 \mathrm{kcal} / \mathrm{mol}$.

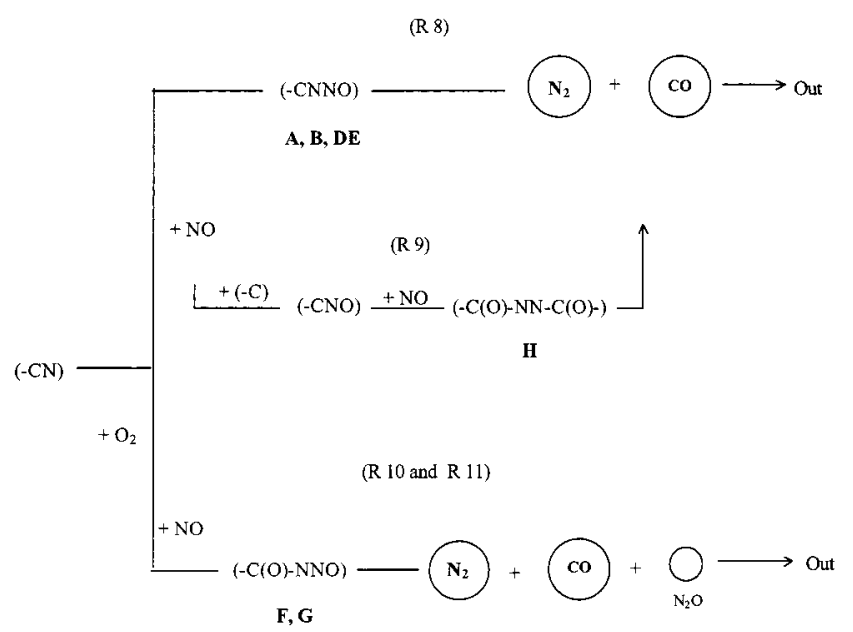

Figure 13. Schematic diagram showing different heterogeneous reactions of the NO molecule with nitrogen active sites on the char. Letters correspond to the NO adsorption complexes formed.

\section{Discusion}

The important pathways for reactions of NO with charcontaining nitrogen determined at the B3LYP level of theory is summarized in Figure 13. In this figure, the intermediates of reactions are identified. The size of the circle corresponds to the thermodynamic probability of reaction obtained from the schematic energy profiles shown in Figures 4, 7, 10, and 12. Two cases for reactions of the NO molecule with nitrogen in the char are considered. The first one is the reaction of the NO molecule in the absence of oxygen in the basal plane (reactions R8 and R9 in Figure 13). In this case, nitrogen in the char will react with the $\mathrm{NO}$ molecule in order to release $\mathrm{CO}$ and $\mathrm{N}_{2}$ predominantly. The second one is the reaction of the NO molecule in the presence of oxygen in the basal plane (reactions R10 and R11 in Figure 13). In this case, nitrogen in the char will react with the NO molecule to release not only $\mathrm{N}_{2}$ but also $\mathrm{N}_{2} \mathrm{O}$ to the gas phase. The $\mathrm{N}_{2}$ evolution in both cases comes from a direct nitrogen-nitrogen interaction between the NO molecule and the carbon-nitrogen model in a side-on approach, while $\mathrm{N}_{2} \mathrm{O}$ evolution comes from a direct nitrogen-nitrogen interaction in the $\mathrm{N}$-down approach. The energies associated with the most important paths of the NO reactions shown in Figure 13 are shown in the reactions below R8-R12.

$$
\begin{gathered}
\mathrm{N} \text { (pyridinic, cyanide) }+\mathrm{NO} \rightarrow \mathrm{N}_{2}+\mathrm{C}(\mathrm{O}) \\
\Delta E=-96.4,-94.1 \mathrm{kcal} / \mathrm{mol}(\mathrm{R} 8) \\
(-\mathrm{CNO})+\mathrm{NO} \rightarrow \mathrm{N}_{2}+\mathrm{C}(\mathrm{O}) \\
\Delta E=-98.1 \mathrm{kcal} / \mathrm{mol}(\mathrm{R} 9) \\
\mathrm{N}\left(\text { Pyridinic) - epoxy Oxygen }+\mathrm{NO} \rightarrow \mathrm{N}_{2}+\mathrm{C}(\mathrm{O})\right. \\
\Delta E=-113.3 \mathrm{kcal} / \mathrm{mol}(\mathrm{R} 10) \\
\mathrm{N}\left(\text { Pyridinic)-epoxy Oxygen }+\mathrm{NO} \rightarrow \mathrm{N}_{2} \mathrm{O}+(-\mathrm{C})\right. \\
\Delta E=-42.6 \mathrm{kcal} / \mathrm{mol}(\mathrm{R} 11) \\
\mathrm{N} \text { (pyridinic, cyanide) }+\mathrm{NO} \rightarrow \mathrm{CO}+(-\mathrm{CNN}) \\
\Delta E=-92.6 \mathrm{kcal} / \mathrm{mol}(\mathrm{R} 12)
\end{gathered}
$$

$\mathrm{C}(\mathrm{O}),(-\mathrm{C})$, and $(-\mathrm{CNN})$ represent an oxygen complex, carbon products, and char-containing nitrogen, respectively. Reaction R8 shows the energy of the NO molecule with a nitrogen in the carbon system forming pyridinic and cyanide groups, respectively. Reaction R9 shows the energy of the NO molecule after another NO molecule has been chemisorbed on the 
carbonaceous surface. Interestingly, reaction energies obtained with three different nitrogen models are almost the same. The $\mathrm{N}_{2}$ desorption from different nitrogen groups has the same thermodynamic probability of reaction as shown in reactions R8 and R9. Reactions R10 and R11 represent the interaction of the NO molecule in the presence of an epoxy oxygen. In this case, the reduction to $\mathrm{N}_{2}$ with a nitrogen on the surface is enhanced by increasing the exothermicity of the reaction in $28 \%$ due to the presence of the oxygen. The evolution of the $\mathrm{N}_{2} \mathrm{O}$ in this case is an exothermic process of $42.6 \mathrm{kcal} / \mathrm{mol}$. Reaction $\mathrm{R} 12$ represents the evolution of $\mathrm{CO}$ for the reaction of $\mathrm{NO}$ with nitrogen in the char. The reaction energy is more than $3.5 \mathrm{kcal} /$ mol higher than those form the evolution of $\mathrm{N}_{2}$. This suggests that the evolution of both $\mathrm{N}_{2}$ and $\mathrm{CO}$ can take place simultaneously.

Although in principle one needs both reaction energies and barrier heights in order to provide a complete picture on the reaction mechanism, for the combustion system under study, reaction energies alone are sufficient to elucidate dominant reaction pathways for the following reasons. First, the operating temperature is often above $1000 \mathrm{~K}$. Second, dominant pathways all involve adsorption of NO with exothermicities of more than $100 \mathrm{kcal} / \mathrm{mol}$ or are followed by an exothermic reaction that yields an overall exothermicity of more than $100 \mathrm{kcal} / \mathrm{mol}$. Thus, thermal energy and heats of reaction are sufficient to surmount any barriers in the subsequent step upon adsorption of NO. Thus, dominant pathways of this combustion system are controlled thermodynamically rather than kinetically.

This study shows that the $\mathrm{N}_{2} \mathrm{O}$ molecule can be obtained from a heterogeneous reaction of the NO molecule with carbonnitrogen systems in the presence of oxygen. However, more theoretical studies are needed in order to have a definite conclusion on the relative importance of the heterogeneous or homogeneous $\mathrm{N}_{2} \mathrm{O}$ formation. For instance, the adsorption of the $\mathrm{N}_{2} \mathrm{O}$ molecule in a carbonaceous material after it has been produced must be taken in to account in order to determine the relative importance of the reduction to $\mathrm{N}_{2}$. Also, the evolution of cyanide compounds from the char-nitrogen models must be studied in order to compare $\mathrm{N}_{2} \mathrm{O}$ formation by heterogeneous release of $\mathrm{HCN}$ followed by homogeneous reaction with NO with the pathway described in this paper. The present paper provides a part of a larger picture where different model compounds and different pathways need to be investigated. It, however, shows the value of density functional theory in unraveling the present confused understanding of the reactions of the oxidation in the presence of NO of chars containing organically bound nitrogen.

\section{Conclusions}

We have carried out a systematic theoretical study using a nonlocal hybrid B3LYP density functional theory to provide insight into the mechanism for $\mathrm{N}_{2} \mathrm{O}$ evolution from combustion of nitrogen-containing char.

Different models of nitrogen-containing char were studied in order to establish the feasibility of nitrous oxide evolution from a heterogeneous process. We found that reaction of an $\mathrm{NO}$ molecule with char yields predominantly $\mathrm{CO}$ and $\mathrm{N}_{2}$ to the gas phase. However, reaction of an NO molecule with charnitrogen in the presence of chemisorbed oxygen can also release $\mathrm{N}_{2} \mathrm{O}$ but as a minor product. Oxygen chemisorbed in the basal plane plays an important role in enhancing the $\mathrm{N}_{2}$ and $\mathrm{N}_{2} \mathrm{O}$ evolution. Additional calculations need to be carried out on different model compounds and for different pathways to $\mathrm{N}_{2}$ and $\mathrm{N}_{2} \mathrm{O}$, particularly those involving sequential heterogeneous and homogeneous reactions.

Acknowledgment. A.F.S. thanks Dr. Baldur Eliasson at ABB Corporate Research LTD, Segelhof, Switzerland, for the support of the research project entitled "A Study of the $\mathrm{NO}_{\mathrm{X}}$ and $\mathrm{N}_{2} \mathrm{O}$ Formation and Reduction During Coal Combustion in Fluidized Beds". This work is supported in part by The National Science Foundation to T.N.T. We also thank the Utah Center for High Performance Computing for computer time support. A.M. thanks Colciencias and the University of Utah for financial support.

\section{References and Notes}

(1) Wójtowicz, M. A.; Pels, J. R.; Moulijn, J. A. Fuel Processing Technol. 1993, 34, 1 .

(2) Pohl, J. H.; Sarofim, A. F. 16th International Symposium on Combustion; The combustion Institute: Philadelphia PA, 1976; p 491.

(3) Baumann, H.; Möller, P. Erdöl, Erdags, Kohle 1991, 44 (1), 29.

(4) Tullin, C. J.; Sarofim, A. F.; Beér, J. K. J. Inst. Energy 1993, 207.

(5) Miller, J. A.; Bowman, C. T. Prog. Energy Combust. Sci. 1989, $15,287$.

(6) Solomon, P. R.; Colket, M. B. Fuel 1978, 57, 749.

(7) Blair, D. W.; Wendt, J. O. L.; Bartok, W. 16th International Symposium on Combustion; The Combustion Institute: Philadelphia, PA, 1976 ; p 475.

(8) Pels, J. R.; Kapteijn, F.; Moulijn, J. A.; Zhu, Q.; Thomas, K. M. Carbon 1995, 1641

(9) Wójtowicz, M. A.; Pels, J. R.; Moulijn, J. A. Fuel 1995, 74, 507.

(10) Thomas, K. M. Fuel 1997, 76, 457.

(11) De Soete, G. G.; Croiset, E.; Richard, J. R. Combust. Flame 1999, 117,140 .

(12) Stanczyk, K. Energy Fuels 1999, 13, 82.

(13) Chambrion, Ph.; Kyotani, T.; Tomita, A. Energy Fuels 1998, 12, 416.

(14) Chambrion, Ph.; Orikasa, H.; Suzuki, T.; Kyotani, T.; Tomita, A. Fuel 1997, 76, 493.

(15) Suzuki, T.; Kyotani, T.; Tomita, A. Ind. Eng. Chem. Res. 1994, 33,2840 .

(16) Chambrion, P.; Kyotani, T.; Tomita, A. Twenty-Seventh International Symposium on Combustion: The Combustion Institute: Philadelphia, PA, 1998; p 3053.

(17) Kyotani, T.; Tomita, A. Ext. Abstr. EUROCARBON 1998.

(18) Kyotani, T.; Tomita, A. J. Phys. Chem. B 1999, 103, 3434.

(19) Krammer, G. F.; Sarofim, A. F. Combust. Flame 1994, 97, 118.

(20) Tullin, C.; Goel, S.; Morihara, A.; Sarofim, A. F.; Beér, J. J. Energy Fuels 1993, 7, 796.

(21) Åmand, L. E.; Leckner, B. Energy Fuels 1993, 7, 1097.

(22) Kilpinen, P.; Hupa, M. Combust. Flame 1991, 85, 94.

(23) Winter, F.; Warth, C.; Loffler, G.; Hofbauer, H. Twenty-sixth International Symposium on Combustion; The Combustion Institute: Philadelphia, PA, 1996; p 3325.

(24) Winter, F.; Wartha, C.; Hofbauer, H. 14th International Conference On Fluidized Bed Combustion, Vancouver, BC, Canada; ASME: Fairfield, NJ, 1997; 1131.

(25) Winter, F.; Löffler, G.; Wartha, C.; Horbauer, H.; Preto, F.; Anthony, E. Can. J. Chem. Eng. 1999, 77, 275.

(26) Jones, J. M.; Harding, A. W.; Brown, S. D.; Thomas, K. M. Carbon 1995, 33, 833 .

(27) Molina, A.; Eddings, E. G.; Pershing, D. W.; Sarofim. A. F. Prog. Energy Combst. Sci. 2000, 26, 507.

(28) Chen, S. G.; Yang, R. T.; Kapteinj, F.; Moulijn, J. N. Ind. Eng. Chem. Res. 1993, 32, 2835.

(29) Chen, N.; Yang, R. T. Carbon 1998, 36, 1061.

(30) (a) Becke, A. D. J. Chem. Phys. 1992, 96, 2155; (b) 1992, 97, 9173; (c) 1993, 98, 5648

(31) Lee, C.; Yang, W.; Parr, R. G. Phys. Rev. B. 1988, 37, 785.

(32) Montoya, A.; Truong, T.; Sarofim, A. F. J. Phys. Chem A, 2000, 104, 6108.

(33) Frisch, M. J.; Trucks, G. W.; Schlegel, H. B.; Scuseria, G. E.; Robb, M. A.; Cheeseman, J. R.; Zakrzewski, V. G.; Montgomery, J. A., Jr.; Stratmann, R. E.; Burant, J. C.; Dapprich, S.; Millam, J. M.; Daniels, A. D.; Kudin, K. N.; Strain, M. C.; Farkas, O.; Tomasi, J.; Barone, V.; Cossi, M.; Cammi, R.; Mennucci, B.; Pomelli, C.; Adamo, C.; Clifford, S.; Ochterski, J.; Petersson, G. A.; Ayala, P. Y.; Cui, Q.; Morokuma, K.; Malick, D. K.; Rabuck, A. D.; Raghavachari, K.; Foresman, J. B.; Cioslowski, J.; 
Ortiz, J. V.; Stefanov, B. B.; Liu, G.; Liashenko, A.; Piskorz, P.; Komaromi, I.; Gomperts, R.; Martin, R. L.; Fox, D. J.; Keith, T.; Al-Laham, M. A. Peng, C. Y.; Nanayakkara, A.; Gonzalez, C.; Challacombe, M.; Gill, P. M. W.; Johnson, B. G.; Chen, W.; Wong, M. W.; Andres, J. L.; Head-Gordon, M.; Replogle, E. S.; Pople, J. A. Gaussian 98, revision A.7; Gaussian, Inc.: Pittsburgh, PA, 1998

(34) Handbook of Chemistry and Physics, 61th ed.; CRC Press: Cleveland, OH, 1978

(35) Chen, N.; Yang, R. T. J. Phys. Chem. A 1998, 102, 6348.
(36) Buenker, R. J.; Philips, R. A. J. Mol. Struct. (THEOCHEM) 1985 , $123,291$.

(37) Zhuang, Q. L.; Kyotani, T.; Tomita, A. Energy Fuels 1994, 8, 714 (38) Orikasa, H.; Suzuki, T.; Kyotani, T.; Tomita, A.; Martin, R. R. 22nd Biennial Conference on Carbon; American Carbon Society: San Diego, CA, 1995; pp 626-627.

(39) Chambrion, P.; Suzuki, T.; Zhang Z-G.; Kyotani, T.; Tomita, A Energy Fuels 1997, 11, 681.

(40) Miettinen, H. Energy Fuels 1996, 10, 197. 